\title{
Comparison of mating behavior of the fiddler crab $U c a$ lactea in relation to density
}

\author{
Misuzu Aoki and Keiji Wada
}

\begin{abstract}
In the fiddler crab Uca lactea, the relative frequencies of two mating types, surface mating and underground mating, were compared between highdensity and low-density areas. The proportions of the two mating types were not different between the two sites. The proportions of wandering females and waving males were not different between the two sites. Thus, the population density of $U$. lactea did not influence the frequency of these mating-related behaviors or the relative frequencies of the two mating types.
\end{abstract}

\section{Introduction}

In fiddler crabs (Uca spp.), two types of mating tactic (surface and underground mating) can occur within species, such as found in Uca lactea (Yamaguchi, 1971), U. beebei (Christy, 1987), U. arcuata (Murai, 1992), U. tetragonon (Murai et al., 1995), and U. perplexa (Nakasone \& Murai, 1998). The adoption of either may be governed by predation risk or population density. Koga et al. (1998) reported that elevated predation risk caused $U$. beebei females to leave their burrows less frequently, which led to an increase in surface mating. De Rivera et al. (2003) found that under high densities, $U$. beebei females wandered more extensively, which led to an increase in underground mating.

In U. lactea (De Haan, 1835), which is distributed in southern Japan, Korea, China, and Taiwan (Naderloo et al., 2010), surface mating occurs when a male approaches a nearby receptive female (Yamaguchi, 2001).
In underground mating, burrow-holding males sometimes attract wandering females by waving their major claw (Murai et al., 1987, Yamaguchi, 2001). Females involved in underground mating must first leave their own burrows and wander on the surface. Although mating success is different between surface and underground mating (Murai et al., 1987), there is no difference in body size of couples engaging in the two types (Yamaguchi, 2001). Thus, the factors that influence the adoption of these mating types in $U$. lactea remain unknown.

In this study, we focused on the effect of population density on the relative frequencies of each mating tactic. If the density increases, we expect that interaction among individuals would increase, producing wandering females interacting with wandering males (Murai et al., 1987). We, therefore, predicted that the proportion of wandering females under the high density is higher than under the low density. Additionally, the number of waving males could increase, concurrent with the increase of wandering females, which leads to the increase of underground mating relative to the surface mating. Thus, we compared the frequencies of each mating type as well as the proportions of wandering female and waving males between high-density and low-density areas to detect a density effect.

Mating behavior.-Uca lactea shows two types of mating behavior in sex-mixed colonies (Yamaguchi, 1971, 2001; Murai et al., 1987). In surface mating, a male courts a nearby female, usually the nearest one. The male leaves his burrow and approaches the female. If the female is receptive, the pair copulates at the entrance of the female's 
burrow. In underground mating, a burrowholding male induces a wandering female into his burrow. Then the male closes the entrance and stays with the female for a few days.

\section{Materials and Methods}

Study area and period.-Field observations were carried out on a tidal flat in the Onosatogawa River Estuary, Osaka Prefecture, during the breeding season of Uca lactea in June to August 2010 (Fig. 1). Observation sites (each $120 \mathrm{~m}^{2}$ ) with different population densities were established. The intertidal height was from 0 to $+4 \mathrm{~cm}$ above mean sea level (MSL) at the high-density site and -13 to $+4 \mathrm{~cm}$ above MSL at the low-density site. At both sites, the entire substratum was muddy sand mixed with gravel. Observations at the two sites were carried out on 9 days ( 8 days around the spring tides and 1 day around the neap tide), with $6 \mathrm{~h}$ of observation ( $2 \mathrm{~h}$ before low tide to $4 \mathrm{~h}$ after low tide) per day.

Behavioral observations.-To record the frequencies of mating behaviors, a $30 \mathrm{~m}^{2}$ area was selected randomly within in each of the observation sites each day. The selected areas were observed for 25-min periods; these observations were repeated six times each day, alternating between the highdensity and low-density sites. For the first 5 min of each period, scan sampling of active crabs was made for 40-70 randomly selected mature crabs $(\mathrm{CW}>11 \mathrm{~mm})$ within the site. Behaviors observed during scan sampling were categorized as "foraging," "encounter," "waving," "wandering," "mating", and "others." After scan sampling, we observed the focal area for $20 \mathrm{~min}$. When copulation was observed on the surface or when a wandering female entered a male's burrow (the female did not reappear on the surface within a few minutes), we recorded the event as a case of mating behavior.

Crab density at each observation site was quantified by counting the number of active crabs in each of five $1 \times 1 \mathrm{~m}$ quadrats, which were placed haphazardly, at low tide on each day. The temperature and salinity of groundwater (seep water in a dug hole) at each site were recorded by an EC METER

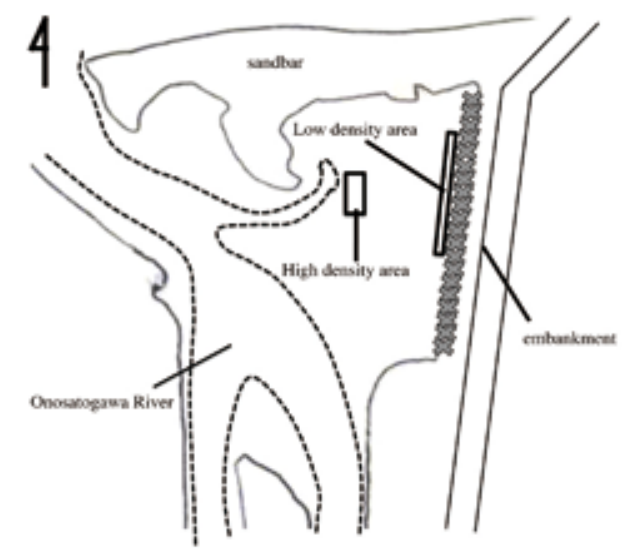

Fig. 1. Map showing the study area in the Onosatogawa River Estuary.

CM-21P (TOA Electronics Ltd., Kobe, Japan).

Data analysis.-Proportional frequencies of each coupling type were compared between the high-density and low-density sites by a G-test. The proportion of wandering females and waving males was also compared between the two sites. The proportion of wandering females was obtained by counting the number of wandering females during each observation period and dividing by the number of active crabs (males and females) in the same period. The proportion of waving males was calculated by counting the number of waving males and dividing by the number of active males. The proportions of wandering females and waving males were compared between the two sites by a MannWhitney's $U$-test or $t$-test; the proportions were compared among study days and among exposure periods relative to the slack low tide by a Kruskal-Wallis test or one-way ANOVA.

\section{Results}

Crab density and environmental conditions.-The density of active $U$. lactea per $1 \mathrm{~m}^{2}$ ranged from 12.0 to 26.3 (mean \pm $\left.\mathrm{SD}=18.11 \pm 5.48 / \mathrm{m}^{2}, \mathrm{~N}=9\right)$ in the highdensity site and 5.2 to 11.2 (mean $\pm \mathrm{SD}=$ 
$8.22 \pm 2.43 / \mathrm{m}^{2}, \mathrm{~N}=9$ ) in the low-density site during the study period; the difference between the sites was statistically significant $(t=-4.95, P<0.01, \mathrm{~N}=9)$. Groundwater temperature ranged from 25.0 to $32.8^{\circ} \mathrm{C}$ (mean $\left.\pm \mathrm{SD}=29.80 \pm 2.65^{\circ} \mathrm{C}, \mathrm{N}=8\right)$ in the highdensity site and 24.9 to $35.1^{\circ} \mathrm{C}$ (mean $\pm \mathrm{SD}$ $=31.03 \pm 3.36^{\circ} \mathrm{C}, \mathrm{N}=8$ ) in the low-density site; the difference between the two sites was not significant $(t=-0.81, P=0.43$ ). The salinity of the groundwater ranged from 0.38 to $1.57 \mathrm{psu}$ (mean $\pm \mathrm{SD}=1.02 \pm 0.43 \mathrm{psu}, \mathrm{N}$ $=8$ ) in the high-density site and 0.50 to 1.99 psu (mean $\pm \mathrm{SD}=0.90 \pm 0.48 \mathrm{psu}, \mathrm{N}=8$ ) in the low-density site; the difference between sites was not significant $(t=-0.50, P=0.63)$.

Mating behavior.-In total, 74 mating events were recorded during the study period. In the high-density site, surface mating was observed on 40 occasions and underground mating was observed on 11 occasions. At the low-density site, surface mating was observed on 19 occasions and underground mating was observed on 4 occasions. The proportion of the two coupling types was not significantly different between the two sites ( $\mathrm{Gadj}=0.17$, $P=0.68)$.

Proportion of wandering females.-There was no significant difference in the proportion of wandering females between the highdensity site (mean $\pm \mathrm{SD}=0.010 \pm 0.014)$ and the low-density site (mean $\pm \mathrm{SD}=0.009 \pm$ $0.014)(Z=0.14, P=0.89)$. The proportion of wandering females differed significantly among the exposure periods (Kruskal-Wallis test, $\left.x^{2}=14.00, P<0.05, d f=5\right)$, being highest during the $2 \mathrm{~h}$ after low tide (Fig. 2a), but did not differ among days $\left(x^{2}=4.16, P=\right.$ $0.65, d f=6)$.

Proportion of waving males.-There was no significant difference in the proportion of waving males between the high-density site (mean $\pm \mathrm{SD}=0.362 \pm 0.158)$ and the lowdensity site (mean $\pm \mathrm{SD}=0.308 \pm 0.192)(t$ $=1.30, P=0.19, d f=72)$. ANOVA revealed that the proportion of waving males differed significantly among the exposure periods $\left(F_{5,68}=6.50, P<0.01\right)$, with the highest proportion occurring during the $2 \mathrm{~h}$ after low

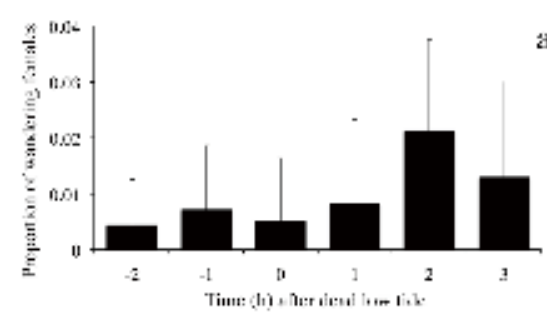

at

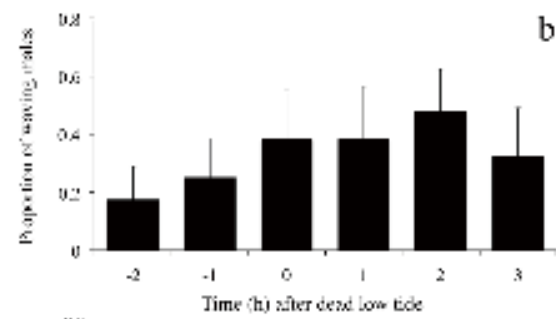

b

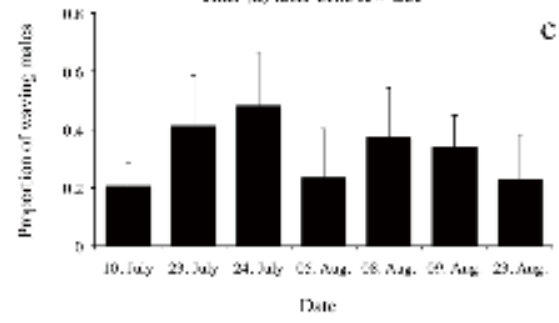

Fig. 2. Frequency of (a) wandering females (proportion of wandering females among active crabs) and (b) waving males (proportion of waving males among active males) for various time points around dead low tide, and (c) waving males on various days throughout the study period.

tide (Fig. 2b), and among study days $\left(F_{6,67}=\right.$ 4.83, $P<0.01$ ), being highest on 24 July (Fig. 2c).

\section{Discussion}

The present study shows that the proportions of the two mating types (surface mating and underground mating) in Uca lactea did not differ between the high-density site and the low-density site, assuming that the proportion of receptive females was the same between the sites. This finding is incongruent with the results of De Rivera et al. (2003), who found that in U. beebei, the proportion of wandering females increased with population density, which led to an increase in the rate of underground mating. In the present study of $U$. lactea, the proportion of wandering females, which may influence the relative rates 
of the two mating types as in $U$. beebei, was not different between the two sites with different population densities. One reason for these results may be an interspecific difference in occurrence of wandering females. The occurrence ratio of wandering female (U. lactea: $1.0 \%$ ) was much lower than that of $U$. beebei $(12.0 \%$ calculated by De Rivera et al. (2003)). In U. beebei, a female wanders by herself in search of a male (Koga et $a l ., 1998)$, whereas in U. lactea harassment by males triggers wandering of females (Murai et $a l .$, 1987). As a consequence the underground mating was extremely lower in U. lactea than the surface mating. Thus, a density effect on mating types was not evident in U. lactea, in which the underground mating is of minor importance.

Moreover, the proportion of waving males, which is associated with underground mating as in Ilyoplax pusilla (Ohata \& Wada, 2009), also did not differ between the two sites. Our finding that the proportions of waving males and wandering females were higher in the same exposure period (Fig. 2) indicates that the proportion of waving males changes in accordance with the proportion of wandering females. If so, the proportion of waving males would not differ between the two sites because of the similar frequency of wandering females.

Predation risk is known to effect the proportions of the two mating types in $U$. beebei (Koga et al., 1998). However, the risk of predation was low at the present study sites because there were few animal predators of $U$. lactea (the grapsoid crab Helice tridens, the whimbrel Numenius phaeopus). Thus, the population density of $U$. lactea influenced neither the proportion of wandering females nor the proportion of waving males, which may explain the lack of any observed differences in mating types between the high- and low-density sites. However, because our data only provide a comparison between sites with different densities, this result should be confirmed by densitymanipulation experiments.

The absence of an influence of population density on mating type is supported by regional differences in mating type. The U. lactea population in Taiwan only shows surface mating (Severinghaus \& Lin, 1990), whereas the Japanese population shows both types of mating behavior (Yamaguchi, 1971, 2001; Murai et al., 1987). This difference is not caused by population density because the density is similar between the Taiwanese population $\left(8.88-17.7 / \mathrm{m}^{2}\right.$; calculated from Severinghaus \& Lin (1990)) and the populations at our study sites (low-density site: $8.82 \pm 2.43 / \mathrm{m}^{2}$; high-density site: $18.11 \pm 5.48 /$ $\mathrm{m}^{2}$ ). The risk of predation by birds may be higher in the Taiwanese population than in the Japanese population, because surface mating increases with a higher risk of predation on U. beebei (Koga et al., 1998). Another possible explanation is that behavioral characteristics inherent to the local populations (Zayasu \& Wada, 2010) produce the difference between the Taiwanese and Japanese populations. As for regional variation in mating type, these possibilities need to be examined in a future study.

\section{Acknowledgements}

Our thanks go to Prof. Y. Yusa and members of the Laboratory of Population and Community Ecology, Nara Women's University, for their valuable comments and support. Review and useful comments on the manuscript by two reviewers are also acknowledged.

\section{Literature Cited}

Christy, J. H., 1987. Female choice and the breeding behaviour of the fiddler crab, Uca beebei. Journal of Crustacean Biology, 7: 624-635.

De Rivera, C. E., Backwell, P. R., Christy, J. H., \& Vehrencamp, S. L., 2003. Density affects female and male mate searching in the fiddler crab, Uca beebei. Behavioral Ecology and Sociobiology, 53: 72-83.

Koga, T., Backwell, P. R. Y., Jennions, M. D., \& Christy, J. H., 1998. Elevated predation risk changes mating behaviour and courtship in a fiddler crab. Proceedings of the Royal Society of London Series B, 265: 1385-1390.

Murai, M., 1992. Courtship activity of wandering and burrow-holding male Uca arcuata. Ethology, 92: 124-134.

- Goshima, S., \& Henmi, Y., 1987. Analysis of the mating system of the fiddler crab, Uca lactea. Animal Behaviour, 35: 1334-1342. 
_, Koga, T., Goshima, S., \& Poovachiranon, S., 1995. Courtship and the evolution of underground mating in Uca tetragonon (Decapoda; Ocypodidae). Journal of Crustacean Biology, 15: 655658.

Naderloo, R., Türkay, M., \& Chen, H. L., 2010. Taxonomic revision of the widefront fiddler crabs of the Uca lactea group (Crustacea: Decapoda: Brachyura: Ocypodidae) in the Indo-West Pacific. Zootaxa, 2500: 1-38.

Nakasone, Y., \& Murai, M., 1998. Mating behavior of Uca lactea perplexa (Decapoda: Ocypodidae). Journal of Crustacean Biology, 18: 70-77.

Ohata, M., \& Wada, K., 2009. Are females of Ilyoplax pusilla (Brachyura: Dotillidae) attracted to groups having more waving males? Journal of Ethology, 27: 191-194.

Severinghaus, L. L., \& Lin, H. C., 1990. The reproductive behaviour and mate choice of the fiddler crab (Uca lactea lactea) in
mid-Taiwan. Behaviour, 113: 292-308.

Yamaguchi, T., 1971. Courtship behavior of a fiddler crab, Uca lactea. Kumamoto Journal of Science Biology, 10: 13-37.

- 2001. The mating system of the fiddler crab, Uca lactea (Decapoda, Brachyura, Ocypodidae). Crustaceana, 74: 389-399.

Zayasu, Y., \& Wada, K., 2010. A translocation experiment explains regional differences in the waving display of the intertidal brachyuran crab Ilyoplax pusilla. Journal of Ethology, 28: 189-194.

Addresses: (MA) (KW) KYOUSEI Science Center for Life and Nature, Nara Women's University, Nara 630-8506, Japan.

Email: (MA) mjiro4203@goo.jp

ReCeIVED: 14 April 2011.

ACCEPTED: 23 June 2011. 